ORIGINAL ARTICLE

\title{
Comparison of efficacy \& safety of Blue Light vs Topical Application of $1 \%$ Clindamycin solution in the treatment of mild to moderate inflammatory Acne Vulgaris
}

\author{
SAIRA MOHSIN ${ }^{1}$, MUHAMMAD NADEEM ${ }^{2}$, SHAHBAZ AMAN ${ }^{3}$, ZAIB $^{4}$, SHEHBAZ ALI ${ }^{5}$ \\ ${ }^{1}$ Consultant Dermatologist, Zahida Walfare Hospital, Lahore \\ ${ }^{2}$ Prof. of Dermatology, Sir Ganga Ram Hospital, Lahore \\ ${ }^{3}$ Professor of Dermatology, Services Institute of Medical Sciences/Services Hospital, Lahore \\ ${ }^{4}$ Assistant Professor of Dermatology, DHQ Teaching Hospital/ Sargodha Medical College, Sargodha \\ ${ }^{5}$ Consultant Dermatologist, Alkhidmat Teaching Mansoorah Hospital, Lahore \\ Correspondence to Dr. Saira Mohsin, Email: drsairamohsin@gmail.com, Cell: 0332-6623822
}

\begin{abstract}
Aim: To compare the efficacy \& safety of blue light vs topical application of $1 \%$ clindamycin solution in the treatment of mild to moderate inflammatory acne vulgaris.

Study Design: Comparative interventional study done in Dermatology Outpatient Department Unit-II, KEMU/ Mayo Hospital, Lahore six months i.e. 1-06-2014 - 30-11-2014

Methodology: After an informed and written consent, 130 patients fulfilling the selection criteria were enrolled in the study and divided in two study groups A \& B by balloting method. At first visit, a detailed history and clinical examination was recorded on a specially designed proforma. The acne was graded according to the acne grading scale of American Academy of Dermatology. ${ }^{4,13}$ Group A was exposed to blue light for twenty minutes twice weekly for eight weeks. Group B was given $1 \%$ clindamycin to apply twice daily for a period of eight weeks. Post- treatment follow up was done for next four weeks. Patients were assessed at $2^{\text {nd }}, 4^{\text {th }}, 6^{\text {th }}, 8^{\text {th }}, 10^{\text {th }}$, and $12^{\text {th }}$ week. All findings and side effects were recorded on a predesigned proforma. To determine the efficacy of treatment, Acne Severity Index (ASI) was used. ${ }^{5}$

Result: Efficacy of treatment [ $\geq 50 \%$ improvement in ASI score] was seen in $39(60 \%)$ patients in blue light group while in clindamycin group it was achieved in $8(12.3 \%)$ patients only. Blue light group had significantly less number of side effects observed in $35(37.23 \%)$ patients while clindamycin group had a higher number of side effects observed in 59 (62.77\%) patients, p-value $=0.013$.

Conclusion: Blue light is more efficacious and safer than topical $1 \%$ clindamycin in the treatment of mild to moderate inflammatory acne vulgaris.

Keywords: Blue light, $1 \%$ Clindamycin, Acne vulgaris
\end{abstract}

\section{INTRODUCTION}

Acne vulgaris is a common, chronic inflammatory disease of pilosebaceous unit affecting $80 \%$ of teenagers between $13-18$ years and $50.9 \%$ of women and $42.5 \%$ of men between the ages of 20 to 29 years ${ }^{1,2,3}$. Topical and systemic antibiotics are mainstay of treatment but there is a rapid increase in the resistance to antibiotics for Propionibacterium acnes, so, there is a need for some alternative therapy. ${ }^{5}$ Phototherapy with blue light is an efficacious \& safe additional therapy ${ }^{6}$. Blue light treatment is a non-UV light therapy, ranging between the wavelength of $405-485 \mathrm{~nm}^{7}$ It is a natural, non-invasive treatment and effective against those strains of Propionibacterium acnes which are resistant to antibiotics ${ }^{7}$. There is photo-excitation of bacterial porphyrins after exposure to blue visible light, due to which singlet oxygen radical is produced which causes endogenous photodynamic destruction of bacteria ${ }^{5,6}$. Light is absorbed by bacterial cells which produces changes in permeability of cell membrane. This change in permeability leads to influx of proton and disruption of $\mathrm{pH}$ gradient across cell membrane which leads to inhibition of growth of $P$. Acnes. ${ }^{5,6}$ Inhibition of

Received on 13-02-2021

Accepted on 23-06-2021 growth and photodynamic demolition of $P$. acnes, both play an important role in the treatment of inflamed acne lesions by blue light. ${ }^{6}$ Clindamycin is a lincosamide antibiotic, active against many gram-positive cocci, anaerobic and microaerophilic gram-positive \& gram-negative organisms including Propionibacteriumacnes. ${ }^{8}$ Its bactericidal action is due to its capability to inhibit ribosomal protein synthesis in target organisms by binding to $50 \mathrm{~S}$ ribosomal subunits. ${ }^{8}$ Different studies have shown excellent results ranging from $34 \%$ to $76 \%$ betterment in acne lesions with blue light therapy ${ }^{5,6,9-12}$. Morton CA et al did a study which showed the average clearance of acne lesions upto $76 \%$ with blue light after 4 weeks of treatment. ${ }^{6}$ Shalita AR et al studied the effect of blue light in the treatment of mild to moderate acne vulgaris. ${ }^{9}$ After eight bi-weekly treatments, inflammatory lesion count decreased upto $60 \%$. Two weeks after last treatment, count further decreased to almost $70 \%{ }^{9}$. Gold $\mathrm{MH}$ et al compared the efficacy of blue light with topical $1 \%$ clindamycin in the treatment of mild to moderate inflammatory acne vulgaris. ${ }^{11}$ Blue light therapy decreased inflammatory lesions count by an average of $34 \%$, as compared to $14 \%$ for $1 \%$ clindamycin solution ${ }^{11}$.

This study was planned to improve the management and provide the patient with best effective \& safe treatment for acne. 


\section{METHODOLOGY}

After approval from ethical committee of KEMU, the study was conducted in Dermatology Outpatient Department Unit-II, KEMU/ Mayo Hospital, Lahore from i.e. 1-06-2014 30-11-2014. After an informed and written consent, 130 patients fulfilling the selection criteria were enrolled in the study and divided in two study groups A \& B by balloting method. At first visit, a detailed history and clinical examination was recorded on a specially designed proforma. The acne was graded according to the Acne Grading Scale of American Academy of Dermatology.4,13 Lesions were counted before starting therapy and photographs were taken at each follow-up visit during \& after treatment. To determine the efficacy of treatment, Acne Severity Index (ASI) was used. ${ }^{5}$ Patients were instructed to cleanse their face before each treatment with an unscented soap or facial cleanser. They were instructed to apply a moisturizing non comedogenic sunscreen with sun protection factor (SPF) 30 after each morning treatment. Group A was exposed to blue light for twenty minutes two times per week (3-4 days interval between treatments) for eight weeks. Blue light source was kept at 5-10 cm from patient's face and eyes of the patients were covered with black goggles. Group B was given 1\% clindamycin solution to apply twice daily for a period of eight weeks. After eight weeks, follow up was done for next four weeks. Patients were assessed at $2^{\text {nd }}, 4^{\text {th }}, 6^{\text {th }}, 8^{\text {th }}, 10^{\text {th }}$ and $12^{\text {th }}$ week in order to compare the efficacy and safety Acne Grading Scale

\begin{tabular}{|l|l|l|l|l|l|}
\hline Acne & Comedones & Papules & Pustules & Nodules/ Cysts & Scar \\
\hline Mild & Several-many & Several & Few & None & No \\
\hline Moderate & Several-numerous & Several & Several & Rare & No \\
\hline Severe & Numerous/Scattered & Numerous & Numerous & Many & Often \\
\hline
\end{tabular}

\section{RESULTS}

Table 1: Comparison of age (years) in both study groups

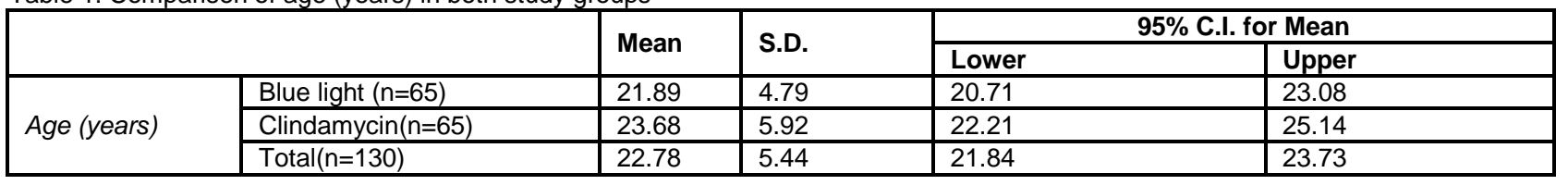

Table 2: Comparison of duration of disease (years) in both study groups

\begin{tabular}{|l|l|l|l|l|l|}
\hline \multicolumn{2}{|c|}{} & \multirow{2}{*}{ Mean } & \multirow{2}{*}{ S.D. } & 95\% C.I. for Mean \\
\cline { 4 - 6 } & & & & Lower & Upper \\
\hline \multirow{2}{*}{$\begin{array}{l}\text { Duration of disease } \\
\text { (years) }\end{array}$} & Blue light $(\mathrm{n}=65)$ & 2.14 & 2.23 & 1.59 & 2.70 \\
\cline { 2 - 6 } & Clindamycin $(\mathrm{n}=65)$ & 1.63 & 1.65 & 1.22 & 2.04 \\
\cline { 2 - 6 } & Total $(\mathrm{n}=130)$ & 1.89 & 1.97 & 1.55 & 2.23 \\
\hline
\end{tabular}

Table 3: Comparison of comedones in both study groups

\begin{tabular}{|l|l|l|l|l|l|}
\hline \multirow{2}{*}{} & \multirow{2}{*}{ Mean } & \multirow{2}{*}{ S.D } & $95 \%$ C.I. for Mean \\
\cline { 3 - 6 } & & & Lower & Upper \\
\hline \multirow{3}{*}{ No. of lesions (before treatment) } & Blue light & 26.86 & 14.76 & 23.20 & 30.52 \\
\cline { 2 - 6 } & Clindamycin & 14.06 & 7.61 & 12.18 & 15.95 \\
\cline { 2 - 6 } & Total & 20.46 & 13.35 & 18.15 & 22.78 \\
\hline \multirow{3}{*}{ No. of lesions 2nd week } & Blue light & 26.74 & 14.44 & 23.16 & 30.32 \\
\cline { 2 - 6 } & Clindamycin & 14.14 & 8.07 & 12.14 & 16.14 \\
\cline { 2 - 6 } & Total & 20.44 & 13.26 & 18.14 & 22.74 \\
\hline \multirow{3}{*}{ No. of lesions 4th week } & Blue light & 25.97 & 13.23 & 22.69 & 29.25 \\
\cline { 2 - 6 } & Clindamycin & 14.57 & 8.06 & 12.57 & 16.57 \\
\cline { 2 - 6 } & Total & 20.27 & 12.32 & 18.13 & 22.41 \\
\hline
\end{tabular}

of blue light with $1 \%$ clindamycin antibiotic solution. All findings and side effects were recorded on a predesigned proforma.

ASI score $=0.25 \times$ comedone number $+1 \times$ papule

Assessment criteria: Criteria of improvement was as follows:

- $\quad<25 \%$ reduction in ASI score was regarded as poor improvement

- $\quad 25-49 \%$ reduction in ASI score was regarded as fair improvement

- $\quad 50-75 \%$ reduction in ASI score was regarded as good improvement

- $\quad>75 \%$ reduction in $\mathrm{ASI}$ score was regarded as

Data Analysis Procedure: Data entry and analysis was done by using SPSS 17. Quantitative variables like age, ber of acne lesions, duration of disease etc., was presented by using mean and standard deviation (SD). Qualitative variables like sex of patient, types of acne lesions etc., were presented by using frequency tables, percentages and appropriate graphs. Repeated measure ANOVA / Friedman test was used to see the reduction in ASI score from the baseline till last follow-up. Clinical improvement and adverse effects of both treatments were compared by using chi-square test. A $p$-value of $\leq 0.05$ was taken as significant. number $+2 \times$ pustule number 


\begin{tabular}{|c|c|c|c|c|c|}
\hline \multirow{3}{*}{$\begin{array}{l}\text { No. of lesions } \\
6 \text { th week }\end{array}$} & Blue light & 25.95 & 13.46 & 22.62 & 29.29 \\
\hline & Clindamycin & 14.42 & 7.92 & 12.45 & 16.38 \\
\hline & Total & 20.18 & 12.43 & 18.03 & 22.34 \\
\hline \multirow{3}{*}{ No. of lesions 8th week } & Blue light & 25.69 & 13.58 & 22.33 & 29.06 \\
\hline & Clindamycin & 14.31 & 7.90 & 12.35 & 16.26 \\
\hline & Total & 20.00 & 12.45 & 17.84 & 22.16 \\
\hline \multirow{3}{*}{ No. of lesions 10 th week } & Blue light & 25.89 & 12.94 & 22.69 & 29.10 \\
\hline & Clindamycin & 14.09 & 7.81 & 12.16 & 16.03 \\
\hline & Total & 19.99 & 12.18 & 17.88 & 22.11 \\
\hline \multirow{3}{*}{ No. of lesions 12 th week } & Blue light & 27.08 & 13.67 & 23.69 & 30.46 \\
\hline & Clindamycin & 13.77 & 9.00 & 11.54 & 16.00 \\
\hline & Total & 20.42 & 13.32 & 18.11 & 22.73 \\
\hline \multirow{3}{*}{$\%$ reduction in no. of lesions } & Blue light & 7.03 & 29.18 & 0.38 & 14.44 \\
\hline & Clindamycin & 8.09 & 54.30 & 6.06 & 22.24 \\
\hline & Total & 7.54 & 43.11 & 0.21 & 15.30 \\
\hline
\end{tabular}

\begin{tabular}{|c|c|c|c|c|c|c|}
\hline & & \multirow{2}{*}{ Mean } & \multirow{2}{*}{ S.D } & \multicolumn{2}{|c|}{ 95\% C.I. for Mean } & \multirow[b]{2}{*}{ p-value } \\
\hline & & & & Lower & Upper & \\
\hline \multirow{3}{*}{ No. of lesions (before treatment) } & Blue light $(n=65)$ & 13.75 & 12.55 & 10.65 & 16.86 & \multirow{3}{*}{0.008} \\
\hline & Clindamycin $(n=65)$ & 9.40 & 3.45 & 8.55 & 10.25 & \\
\hline & Total $(n=130)$ & 11.58 & 9.42 & 9.94 & 13.21 & \\
\hline \multirow{3}{*}{ No. of lesions 2nd week } & Blue light $(\mathrm{n}=65)$ & 11.20 & 4.00 & 10.21 & 12.19 & \multirow{3}{*}{$<0.001$} \\
\hline & Clindamycin $(n=65)$ & 8.77 & 2.74 & 8.09 & 9.45 & \\
\hline & Total $(n=130)$ & 9.98 & 3.63 & 9.36 & 10.61 & \\
\hline \multirow{3}{*}{ No. of lesions 4th week } & Blue light $(n=65)$ & 9.17 & 3.37 & 8.33 & 10.00 & \multirow{3}{*}{0.007} \\
\hline & Clindamycin $(n=65)$ & 7.78 & 2.32 & 7.21 & 8.36 & \\
\hline & Total $(n=130)$ & 8.48 & 2.97 & 7.96 & 8.99 & \\
\hline \multirow{3}{*}{ No. of lesions 6th week } & Blue light $(n=65)$ & 7.62 & 3.18 & 6.83 & 8.40 & \multirow{3}{*}{0.111} \\
\hline & Clindamycin $(n=65)$ & 6.86 & 2.07 & 6.35 & 7.37 & \\
\hline & $\operatorname{Total}(n=130)$ & 7.24 & 2.70 & 6.77 & 7.71 & \\
\hline \multirow{3}{*}{ No. of lesions 8th week } & Blue light $(n=65)$ & 5.15 & 2.35 & 4.57 & 5.74 & \multirow{3}{*}{0.007} \\
\hline & Clindamycin $(n=65)$ & 6.51 & 3.26 & 5.70 & 7.31 & \\
\hline & Total $(n=130)$ & 5.83 & 2.91 & 5.33 & 6.34 & \\
\hline \multirow{3}{*}{ No. of lesions 10 th week } & Blue light $(n=65)$ & 4.80 & 2.43 & 4.20 & 5.40 & \multirow{3}{*}{$<0.001$} \\
\hline & Clindamycin $(n=65)$ & 6.82 & 2.14 & 6.28 & 7.35 & \\
\hline & Total $(n=130)$ & 5.81 & 2.50 & 5.37 & 6.24 & \\
\hline \multirow{3}{*}{ No. of lesions 12 th week } & Blue light $(n=65)$ & 4.85 & 2.24 & 4.29 & 5.40 & \multirow{3}{*}{0.001} \\
\hline & Clindamycin $(n=65)$ & 6.69 & 2.11 & 6.17 & 7.21 & \\
\hline & Total $(n=130)$ & 5.77 & 2.35 & 5.36 & 6.18 & \\
\hline \multirow{3}{*}{$\%$ reduction in no. of lesions } & Blue light $(n=65)$ & 61.68 & 9.78 & 59.25 & 64.10 & \multirow{3}{*}{$<0.0001$} \\
\hline & Clindamycin $(n=65)$ & 27.28 & 16.94 & 23.09 & 31.48 & \\
\hline & Total $(n=130)$ & 44.48 & 22.08 & 40.65 & 48.31 & \\
\hline
\end{tabular}

Table 5: Comparison of pustules in both study groups

\begin{tabular}{|c|c|c|c|c|c|c|}
\hline & & \multirow{2}{*}{ Mean } & \multirow{2}{*}{ S.D } & \multicolumn{2}{|c|}{ 95\% C.I. for Mean } & \multirow{2}{*}{ p-value } \\
\hline & & & & Lower & Upper & \\
\hline \multirow{3}{*}{ No. of lesions (before treatment) } & Blue light $(n=65)$ & 6.43 & 3.48 & 5.57 & 7.29 & \multirow{3}{*}{0.161} \\
\hline & Clindamycin $(n=65)$ & 7.20 & 2.68 & 6.54 & 7.86 & \\
\hline & Total $(n=130)$ & 6.82 & 3.12 & 6.27 & 7.36 & \\
\hline \multirow{3}{*}{ No. of lesions 2nd week } & Blue light $(n=65)$ & 6.06 & 2.94 & 5.33 & 6.79 & \multirow{3}{*}{0.018} \\
\hline & Clindamycin $(n=65)$ & 7.37 & 3.25 & 6.56 & 8.18 & \\
\hline & Total $(n=130)$ & 6.72 & 3.16 & 6.17 & 7.26 & \\
\hline \multirow{3}{*}{ No. of lesions 4th week } & Blue light $(n=65)$ & 4.85 & 2.84 & 4.14 & 5.55 & \multirow{3}{*}{0.009} \\
\hline & Clindamycin $(n=65)$ & 6.29 & 3.31 & 5.47 & 7.11 & \\
\hline & Total $(n=130)$ & 5.57 & 3.16 & 5.02 & 6.12 & \\
\hline \multirow{3}{*}{ No. of lesions 6th week } & Blue light $(n=65)$ & 3.91 & 2.75 & 3.23 & 4.59 & \multirow{3}{*}{0.006} \\
\hline & Clindamycin $(n=65)$ & 5.65 & 4.23 & 4.60 & 6.69 & \\
\hline & Total $(n=130)$ & 4.78 & 3.66 & 4.14 & 5.41 & \\
\hline
\end{tabular}




\begin{tabular}{|l|l|l|l|l|l|}
\multirow{3}{*}{ No. of lesions 8th week } & Blue light $(\mathrm{n}=65)$ & 2.22 & 2.29 & 1.65 & 2.78 \\
\cline { 2 - 6 } & Clindamycin( $(\mathrm{n}=65)$ & 4.28 & 3.32 & 3.45 & 5.10 \\
\cline { 2 - 6 } & Total & 3.25 & 3.03 & 2.72 & 3.77 \\
\hline \multirow{3}{*}{ No. of lesions 10th week } & Blue light & 1.65 & 1.80 & 1.20 & 2.09 \\
\cline { 2 - 6 } & Clindamycin & 4.23 & 2.64 & 3.58 & 4.89 \\
\cline { 2 - 6 } & Total & 2.94 & 2.60 & 2.49 & 3.39 \\
\hline \multirow{3}{*}{ No. of lesions 12th week } & Blue light & 2.32 & 2.11 & 1.80 & 2.85 \\
\cline { 2 - 6 } & Clindamycin & 4.38 & 1.68 & 3.97 & 4.80 \\
\cline { 2 - 6 } & Total & 3.35 & 2.16 & 2.98 & 3.73 \\
\hline \multirow{2}{*}{$\%$ reduction in no. of lesions } & Blue light & 70.09 & 26.10 & 63.63 & 76.56 \\
\cline { 2 - 5 } & Clindamycin & 37.86 & 13.43 & 34.54 & 41.19 \\
\cline { 2 - 5 } & Total & 70.09 & 26.10 & 49.42 & 58.53 \\
\hline
\end{tabular}

Table 6: Comparison of asi scores in both study groups

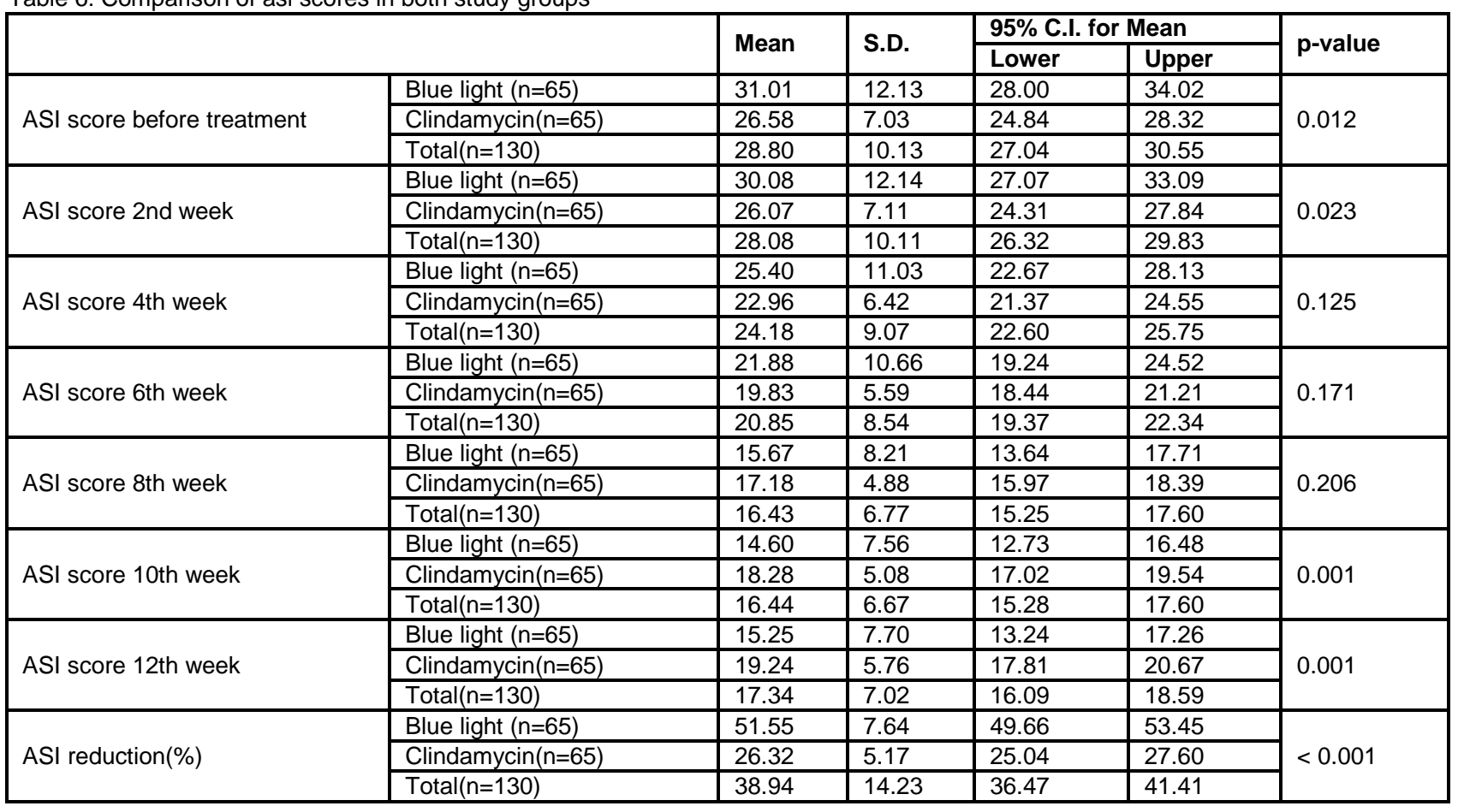

Table 7: Comparison of efficacy in both study groups

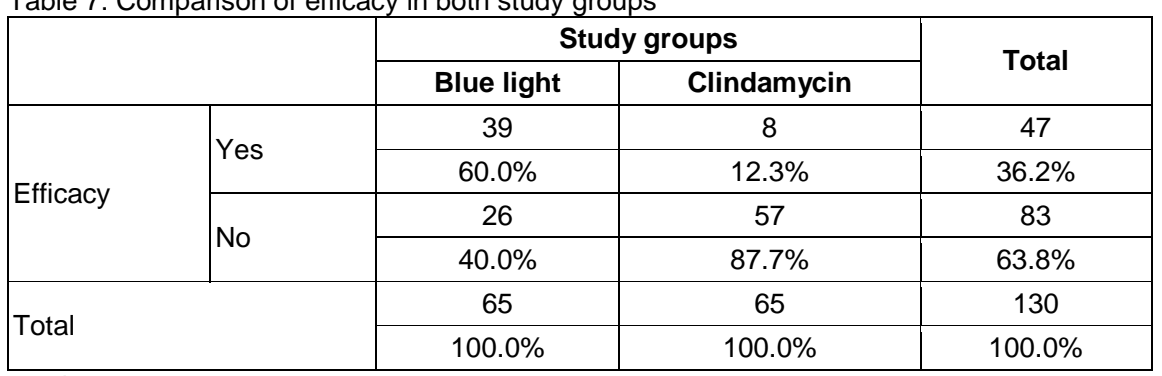

p-value $<0.001$

Table 8: Comparison of side effects in both study groups

\begin{tabular}{|l|c|c|c|}
\hline \multirow{2}{*}{} & \multicolumn{2}{|c|}{ Study groups } & \multirow{2}{*}{ p-value } \\
\cline { 2 - 3 } & Blue light & Clindamycin & \\
\hline Burning 2nd week & 0 & 1 & 0.315 (insignificant) \\
\hline Burning 4th week & 0 & 3 & 0.080 (insignificant) \\
\hline Burning 6th week & 3 & 4 & 0.689 (insignificant) \\
\hline Burning 8th week & 0 & 7 & 0.007 (significant) \\
\hline Burning $8^{\text {th }}-12^{\text {th }}$ week & 0 & 0 & -- \\
\hline
\end{tabular}




\begin{tabular}{|l|c|c|c|}
\hline Itching 2nd week & 4 & 4 & 1 (insignificant) \\
\hline Itching 4th week & 13 & 21 & 0.11 (insignificant) \\
\hline Itching 6th week & 23 & 34 & 0.052 (insignificant) \\
\hline Itching 8th week & 10 & 29 & 0.000 (significant) \\
\hline Itching 10th week & 0 & 11 & 0.001 (significant) \\
\hline Itching 12th week & 0 & 3 & 0.80 (insignificant) \\
\hline Dryness 2nd week & 1 & 0 & 0.315 (insignificant) \\
\hline Dryness 4th week & 17 & 8 & 0.045 (significant) \\
\hline Dryness 6th week & 26 & 31 & 0.377 (insignificant) \\
\hline Dryness 8th week & 10 & 35 & $<0.001$ (significant) \\
\hline Dryness 10th week & 0 & 3 & 0.080 (insignificant) \\
\hline Dryness 12th week & 0 & 2 & 0.154 (insignificant) \\
\hline Erythema 4th week & 6 & 3 & 0.30 (insignificant) \\
\hline Erythema 6th week & 4 & 15 & 0.006 (significant) \\
\hline Erythema 8th week & 3 & 28 & $<0.001$ (significant) \\
\hline Erythema 10th week & 0 & 1 & 0.135 (insignificant) \\
\hline Peeling 6th week & 0 & 3 & 0.80 (insignificant) \\
\hline Peeling 8th week & 0 & 1 & 0.315 (insignificant) \\
\hline Any Other 6th week & 0 & 2 & 0.154 (insignificant) \\
\hline
\end{tabular}

\section{DISCUSSION}

This study was planned to improve the management and provide the patient with best effective \& safe treatment for acne. The mean age of patients was $22.78 \pm 5.44$ years in our study, which correlates with the study by Wheeland RG in which mean age of patients was $22 \pm 6.7$ years. ${ }^{10}$ These results show that acne is more prevalent among this age group. This also correlates well with the study performed by Collier $\mathrm{CN}$ et al which shows that acne affects at higher rates between 20-29 years. ${ }^{3}$ Acne Grading Scale of American Academy of Dermatology was used in this study to classify patients having mild to moderate inflammatory acne. Same grading scale was used by Rahman MM et al in his study ${ }^{13}$.

The results of our study show that mean number of comedonal lesions was statistically same from baseline till $12^{\text {th }}$ week in both groups. No significant difference was found in \% reduction of comedonal lesions between both groups. This is in accordance with the study performed by Morton CA et al which showed that Blue light treatment had little effect on the number of comedones. ${ }^{6}$ It also correlates well with the study performed by Lookingbill DP et al which showed that topical Clindamycin alone is not effective in reducing non-inflammatory lesions ${ }^{14}$.

The results of our study show that in Blue light group the mean \% reduction in the number of papules and pustules was 61.68 and 70.09 respectively. This result is in accordance with the studies performed by Shalita and Papageorgiou which showed that Blue light is effective in reducing inflammatory lesions of acne vulgaris $(60 \%)^{15,16}$.

Morton CA observed the average reduction in inflammatory lesions was upto $73 \%$ with Blue light. ${ }^{6}$ Wheeland RG showed that Blue light is effective upto $46 \%$ in reducing the inflammatory lesions. ${ }^{10}$ Similarly Gold $\mathrm{MH}$ showed that Blue light is effective upto $41.03 \%$ in reducing the inflammatory lesions ${ }^{12}$. This difference in the results of various studies could be explained by the fact that different study tools were used in these studies and there may be different response pattern among study groups and the time to reach the optimum clearance differed between subjects. The results of our study show that in Clindamycin group mean \% reduction in the number of papules and pustules was 27.28 was 37.86 respectively. This result is in accordance with the study performed by Lookingbill DP et al which showed that reduction of inflammatory lesions was upto $35 \%$ with Clindamycin ${ }^{14}$.

Present study reported that efficacy of Blue light was significantly higher when compared to Clindamycin in terms of reduction of ASI score as (51.55\% vs. $26.32 \%)$. Similar study was performed by Gold $\mathrm{MH}$ et al which showed that Blue light was more effective than topical $1 \%$ Clindamycin as $(34 \% \text { vs. } 14 \%)^{11}$.

Present study showed that Blue lightis moresafe than Clindamycin. As 37\% patients experienced side effects in Blue light group and 62\% patients in Clindamycin group. Most frequently observed side effects were itching and dryness. Mild erythema was observed in few patients. Arruda LHF observed that only $23.3 \%$ patients hadmild adverse effects characterized by desquamation and dryness with Blue light treatment ${ }^{9}$. Wheeland $R G$ also show that53 percent of subjects agreed that the Blue light treatment has less side effects than traditional acne treatments. Most frequently observed side effect was minimal and transient skin dryness ${ }^{10}$. Faghihi $\mathrm{G}$ et al observed dryness (18\%) and mild erythema (25\%) with Blue light treatment. ${ }^{5}$

So according to the result of our study we propose that Blue light therapy significantly reduces inflamed acne lesions, with mild side effects, and offers an effective and safe treatment for acne vulgaris. This study is consistent with previous reports of Blue light used in acne and suggests that Blue light phototherapy deserves inclusion in the list of therapeutic options for patients with mild to moderate acne. Therapies that avoid oral ingestion of medication and minimize topical applications are likely to 
be popular with patients. But compliance is major problem because patient has to go to the treatment center twice a week to undergo Blue light applications. So further studies are required to observe optimum efficacy with the shortest possible duration and number of treatments. We also suggest that further studies are required as regards the use of other treatment options in conjunction with Blue light therapy to provide an effective therapy combination.

\section{CONCLUSION}

Blue light therapy is effective, safe and favorable as compared to topical $1 \%$ clindamycin in patients with mild to moderate acne. Its gentleness on the skin offers a better choice in patients who cannot use antibiotics or topical irritating therapies or it may be used as an adjuvant therapy.

\section{Conflict of interest: Nil}

\section{REFERENCES}

1. Purdy S, De Berker D. Acne Vulgaris. ClinEvid [on line] 2008 [cited 2008 May 15]. Available from: http://www.ncbi.nlm.nih.gov/pmc/articles/PMC2907987/.

2. OchsendorfF. Acne vulgaris. CME Dermatol 2009; 4(1): 3651.

3. Collier CN, Harper JC, Cafardi JA, Cantrell WC, Wang $\mathrm{W}$, Foster $\mathrm{KW}$, et al. The prevalence of acne in adults 20 years and older. J Am AcadDermatol2008; 58(1):56-9.

4. Yadav N, Singh A, Chatterjee A, Belemkar S. Evaluation of Efficacy and Safety of Perfect Face Gel and Perfact Face Tablets in Management of Acne. J ClinExpDermatol Res 2011; 2(2): 118.

5. Faghihi G, Vali A, Asilian A, Radan MR, Esteki H, Elahidost M. Comparative efficacy of filtered blue light (emitted from sunlight) and topical erythromycin solution in acne treatment: a randomized controlled clinical trial. J Pak AssocDermatol $2011 ; 21(3): 179-84$.
6. Morton CA, Scholefield RD, Whitehurst C, Birch J.An open study to determine the efficacy of blue light in the treatment of mild to moderate acne.J Dermatol Treat 2005; 16(4): 219-23.

7. Blue Light For Acne Treatment [online] Available from: http://www.intelligentacnetreatment.com/Blue-Light-AcneTreatments/33.htm

8. Whitney $\mathrm{KM}$, Ditre CM. Anti-inflammatory Properties of Clindamycin: A Review of its Use in the Treatment of Acne Vulgaris. Clin med insight: Dermatol 2011; 4: 27-41.

9. Arruda LHF, Kodani V, Bastos Filho A, Mazzaro CB. A prospective, randomized, open and comparative study to evaluate the safety and efficacy of blue light treatment versus a topical benzoyl peroxide $5 \%$ formulation in patients with acne grade II and III. An Bras Dermatol 2009; 84(5): 463-8

10. Wheeland RG, Koreck A. Safety and Effectiveness of a New Blue Light Device for the Self-treatment of mild-to-moderate Acne. J ClinAesthetDermatol 2012; 5(5): 25-31

11. Gold MH, Rao J, Goldman MP, Bridges TM, Bradshaw VL, Boring $\mathrm{MM}$, et al. A multicenter clinical evaluation of the treatment of mild to moderate inflammatory acne vulgaris of the face with visible blue light in comparison to topical $1 \%$ clindamycin antibiotic solution. J Drugs Dermatol 2005; 4(1): 64-70.

12. Gold MH, Andriessen A, Biron J, Andriessen H. Clinical Efficacy of Self-applied Blue Light Therapy for Mild-toModerate Facial Acne. J ClinAesthetDermatol2009;2(3): 4450.

13. Rahman MM, Khondker L, Hazra SC, Khan MSI. Association of serum testosterone with acne vulgaris in women-A case control study. J Pak AssocDermatol2012; 22: 105-11.

14. Lookingbill DP, Chalker DK, Lindholm JS, Katz HI, Kempers $\mathrm{SE}$, Huerter CJ,et al. Treatment of acne with a combination clindamycin/benzoyl peroxide gel compared with clindamycin gel, benzoyl peroxide gel and vehicle gel: combined results of two double-blind investigations. J Am AcadDermato/1997; 37(4): 590-5.

15. Shalita AR, Harth Y, Elman M. Acne PhotoClearing (APCTM) using a novel, high-Intensity, enhanced, Narrow-band, Blue light source. Clinical Application Notes.

16. Papageourgiou $P$, Katsambas $A$, Chu A. Phototherapy with blue $(415 \mathrm{~nm})$ and red $(660 \mathrm{~nm})$ light in the treatment of acne vulgaris. Br J Dermatol2000;142:973-8. 